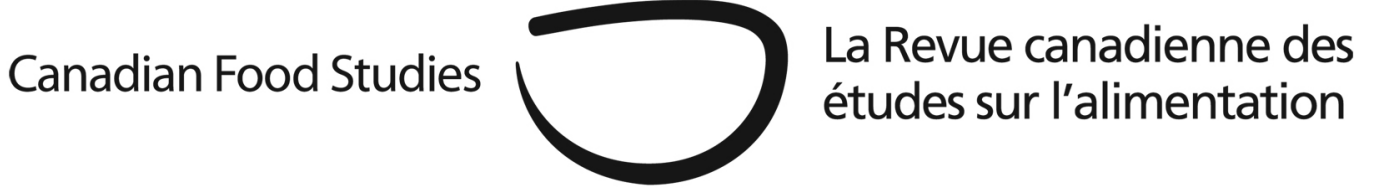

Original Research Article

\title{
Organic vs. local: Comparing individualist and collectivist motivations for "ethical" food consumption
}

Shyon Baumann ${ }^{a^{*}}$, Athena Engman ${ }^{b}$, Emily Huddart-Kennedyc, Josée Johnston ${ }^{d}$

a Associate Professor, Department of Sociology, University of Toronto

${ }^{b}$ Ph.D. Candidate, Department of Sociology, University of Toronto

c Assistant Professor, Department of Sociology, Washington State University

d Professor, Department of Sociology, University of Toronto

\begin{abstract}
We extend prior research on "ethical” food consumption by examining how motivations can vary across demographic groups and across types of ethical foods simultaneously. Based on a survey of food shoppers in Toronto, we find that parents with children under the age of 5 are most likely to report intention to purchase organic foods and to be primarily motivated by health and taste concerns. In contrast, intention to purchase local food is motivated by collectivist concerns-the environment and supporting the local economy — and is associated with educated, White, women consumers. In addition to highlighting this distinction in motivations for organic vs. local food consumption, we also argue that the predominant "individualist" and "collectivist” framing in the scholarly literature should be reformulated to accommodate an intermediate motivation. Organic food consumption is often motivated by a desire to consume for others (e.g. children) in ways that are neither straightforwardly individualist nor collectivist, but rather exemplify a caring motivation that is intermediate between the two.
\end{abstract}

Keywords: ethical consumption; organic food; local food; consumer motivations; caring consumption 


\section{Introduction}

The ethical consumer features prominently in modern discourse on citizenship and morality. A much-studied, often-critiqued, and often-praised practice, ethical consumption is alternately termed "green consumerism” (Schuitema \& De Groot, 2015), "sustainable consumption” (Lundblad \& Davies, 2016), or conscious consumption (Willis \& Schor, 2012). It refers to consumption that is thought to simultaneously pursue two distinct classes of motivations. On the one hand, ethical consumption, like consumption writ large, pursues individual goals and desires. On the other hand, it marries these self-oriented motivations with a desire to pursue "sustainability and social harmony" (Johnston, 2008), or reflect "personal and moral beliefs" (Crane \& Matten, 2003). Ethical consumption, then, pursues both individualist motivations and collectivist motivations (Schrank \& Running, 2016). ${ }^{1}$

Increasingly, scholars are turning to the domain of food shopping to understand the motivations and contradictions of the ethical consumer. Two common types of ethical foods are organic and local. In much of the popular discourse for local and organic foods, individualist and collectivist motivations are framed not as competing, but as complementary. That is, consumers bring both individualist and collectivist ideals to bear on their purchasing decisions. Surprisingly little research compares motivations to consume organic and local foods by asking participants about these forms of ethical consumption simultaneously. In the existing literature on sociodemographic and motivational patterns behind "organic" and "local" (defined below) food consumption, several patterns exist (e.g., regarding the role of gender and health concerns) alongside a few inconsistencies (e.g., regarding the role of income) (Hughner, McDonah, Prothero, Shultz II, \& Stanton, 2007; Tregear \& Ness, 2005). There is, then, a need for further research on these questions.

We set out to determine whether and on what basis organic and local food can be conceptualized as distinct forms of ethical consumption. Our findings paint an intriguing picture of the demographic features and motivations that differentiate intention to purchase organic vs. local food. Because intentions precede consumption behaviours, our findings are relevant for understanding what sets organic food consumers apart from local food consumers. This picture allows us to make important contributions regarding how organic and local food can be conceptualized as distinct forms of ethical consumption.

\section{Consumer demographics and motivations for ethical consumption}

There is considerable literature that has investigated consumer orientation toward various forms of ethical consumption and the factors that motivate them. While this literature has made great progress, a clearer understanding of ethical consumption requires analysis of its narrower forms,

\footnotetext{
${ }^{1}$ Other terms that are employed to capture this distinction include personal vs. societal (Bianchi \& Mortimer, 2015) or consumer-minded vs. civic-minded (Johnston, 2008). We see these terms as all centering on a distinction between self-oriented and other-oriented concerns.
} 
because particular moral issues can vary by realm and by product. For example, some consumption choices are more obviously implicated in questions of environmental degradation (e.g., automobiles, beef), while others invoke questions of human rights, labor justice or social inequality (e.g., clothing, coffee). Different kinds of ethical consumption can vary in their significance and in their appeal to consumers, and prior research shows that there is considerable awareness among consumers of these differences (Jensen \& Mørkbak, 2013).

To gain a better understanding of ethical consumption dynamics, many researchers have studied ethical consumption in food, and specifically organic and local foods. Organic food research is facilitated by the existence of certification bodies, which allow for the definition of organic food to be relatively clear in the minds of consumers. Although certification standards vary, organic generally refers, in the minds of consumers, to the growing of food without synthetic chemicals, genetic modification, and with high standards for the treatment of livestock. Local food research must contend with the lack of a standard definition. Definitions of local are flexible, but the smaller the distance between sites of food production and consumption, the more local food is. We review the research on consumer sociodemographics and motivations separately for organic and local foods to allow for comparisons.

\section{Organic}

\section{Sociodemographics}

Hughner et al. (2007), in their review of the literature on who buys organic food, find variation across studies but several consistent themes as well. They find that most research reports that organic consumers are female, that younger consumers hold more positive attitudes towards organic food, and that older consumers are more likely to buy organic food. In contrast, the findings on income and education as predictors of organic consumption and predictors of attitudes towards organic food were mixed.

Other research published more recently by Hughner et al. (2007) supports the idea that women purchase more organic food or have more positive attitudes toward organic food (Aguirre, 2007; Akgüngör, Miran, \& Abay, 2010; Arvola, \& Hursti, 2001; Gonzalez, 2009; Hamazoui, Essoussi, \& Zahaf, 2008; Lockie, Lyons, Lawrence, \& Mummery, 2002; Lodorfos \& Dennis, 2008; Magnusson, McEachern, \& McClean, 2002; Quah \& Tan, 2009; Sangkumchaliang \& Huang, 2012; Sonderskov \& Daugbjerg, 2011). ${ }^{2}$

Regarding the relationship between education and consumers’ propensity to purchase and/or support organic food products, most recent research finds a positive associate between the two (Aguirre, 2007; Curl et al. 2013; Dettman \& Dimitri, 2009; Dimitri \& Dettman, 2012; Hamazoui et al., 2008; Lockie et al., 2002; Magnusson et al., 2001; Quah \& Tan, 2009; RoitnerSchobesberger, Darnhofer, Somsook, \& Vogl, 2008; Sangkumchaliang \& Huang, 2012;

\footnotetext{
${ }^{2}$ A very small minority of studies fail to support this predominant finding (Roitner-Schobesberger et al., 2008; Zepeda and Li, 2007).
} 
Thøgersen \& Zhou, 2012; Zepeda \& Li, 2007). In contrast, the relationship between income and organic food consumption is not clearly established, with some studies finding evidence for a positive relationship (see, e.g., Aguirre 2007; Dimitri \& Dettman, 2012; Krystallis, Vassallo, Chryssohoidis, \& Perrea, 2008; Roitner-Schobesberger et al., 2008), and others finding a lack of a relationship (Kriwy \& Mecking, 2012; Zepeda \& Li, 2007) or very weak or nonlinear relationships (Curl et al., 2013; Dettman \& Dimitri, 2009; Haghiri, Hobbs, \& McNamara, 2009; Lockie et al., 2002).

The relationship between organic food and age is likewise complicated, with a few studies finding that younger consumers may be more confident in labelling schemes and have positive attitudes towards organic foods (Magnusson et al., 2001; Sønderskov \& Daugbjerg, 2011) or purchasing organic foods more frequently (Curl et al., 2013), while others find that older consumers are actually purchasing organic products more frequently (Haghiri et al., 2009; Sangkumchaliang \& Huang, 2012), or no relationship with age (Lodorfos \& Dennis, 2008).

\section{Motivations}

Regarding motivations behind purchasing organics, there is a consistent finding that health concerns are paramount. In their review of 277 empirical studies, Hemmerling, Hamm, and Spiller (2015) find that health protection (described as individualist) is by far the most important among all motivations for purchasing organic food, with the individualist motivation of taste a distant second, and the collectivist motivation of environmental protection third (p. 283). In a range of other studies in the literature, this finding about the ranking of motivations for organic food purchasing is supported. Health concerns are primary, followed by a preference for the perceived better taste or freshness of organics, while the perceived environmentally-friendly practices of organic food production are typically a minor motivation for most consumers (Adams \& Salois, 2010; Aguirre, 2007; Ahmad \& Juhdi, 2010; Gonzalez, 2009; Haghiri et al., 2009; Hamazoui et al., 2008; Lockie et al., 2002; Lodorfos \& Dennis, 2008; McEachern \& McClean, 2002; Roitner-Sangkumchaliang \& Huang, 2010; Schobesberger et al., 2008; Thøgersen \& Zhou, 2012).

\section{Local}

\section{Sociodemographics}

Unlike organic food consumption, local food consumption behaviors and attitudes are not strongly and consistently associated with any particular demographic variables in prior research, with most studies finding very weak or non-significant relationships (Bingen, Sage, \& Sirieix, 2011; Brown, 2003; Cranfield, Henson, \& Blandon, 2012; Tregear \& Ness, 2005; Zepeda \& Li, 2006). While gender is mostly not a significant predictor of local food consumption, a small minority of studies find that women are more likely to buy local food (Khan \& Prior, 2010; 
Megicks, Memery, \& Angell, 2012). Similarly, although most studies do not find any relationship with age, a minority of studies finds that older (approximately 50+) consumers are more likely to purchase local food (Khan \& Prior, 2010). Existing research typically reports nonsignificant effects for income and education on intention to purchase local food (Megicks et al., 2012; Zepeda \& Li, 2006).

\section{Motivations}

Prior research on the motivations behind consumption of local food supports a focus on several motivations. In contrast to the convergence in the literature regarding motivations for organic food, studies vary in their identification of the most important motivations for purchasing organic food. Across and within studies, consumers are found to be influenced by the collectivist motivations of desire to support local producers and/or the local economy as well as to protect the environment, alongside the individualist motivations for food that is fresher, tastes good, and is perceived to be healthier (Adams \& Salois, 2010; Aguirre, 2007; Brown, 2003; Carpio \& Isengildina-Massa, 2009; Cranfield et al., 2012; Khan \& Prior, 2010; Megicks et al., 2012; Tregear \& Ness, 2005; Weatherell, Tregear, \& Allinson, 2003; Zepeda \& Deal, 2009).

Overall, we find little consensus in the literature concerning the sociodemographic correlates of orientations in favor of local food purchasing, and there appears to be evidence that consumers hold a range of individual and collectivist motivations. For both organic and local food, motivations emerge as stronger predictors of intention to purchase than do sociodemographic variables. Regarding organic food, there is more consensus on a few sociodemographic correlates, and on the priority of individualist motivations over collectivist. It is clear that further research is still needed. At the same time, the individualist motivation of health underlying an orientation in favor of organic food should be further examined. Recent research by Lee (2016) finds that the presence of young children in the household is a very strong predictor of intention to purchase organic food. This research is in line with a study by Reifer and Hamm (2011), which finds that among families who frequently consume organic food, consumption shifts away from organics as the children become adolescents. These findings raise the question of how to understand the health motivation for organic consumption when the health of children, rather than only the self, is involved.

\section{Methods}

\section{Data collection}

This paper employs intercept survey data on consumers' food shopping intentions. The survey was designed by the authors to connect intentions to purchase ethical foods to sociodemographics and motivations. The survey was administered in Toronto by four research 
assistants working in teams at a variety of food shopping locations, which included both discount and upmarket chain grocery stores, as well as farmer's markets. ${ }^{3}$ The research assistants were instructed to approach adult shoppers randomly and ask them to complete a paper copy of the survey, which required between five and ten minutes to complete. ${ }^{4}$ The times and days of survey administration were varied to ensure that respondents were reached across different times of day and different days of the week (both weekdays and weekends). The total number of surveys administered was 1,200, and after dropping cases with missing data on the variables we analyze, our models employ samples of 917 and 941. The descriptive statistics are presented in Table 1. The sample matches well the general Toronto population in terms of racial minority status, household income, education levels, and age, with a slight underrepresentation of those over 60 years of age. Women are overrepresented relative to their proportion in the population, but not relative to their disproportionate role as food shoppers in the household (Bureau of Labor Statistics, 2013). All questions were pretested and screened for validity and reliability with required edits made prior to data collection.

Participants were offered a coffee-shop gift card or a high-quality chocolate bar as an incentive for participation. They received the incentive after completing the survey; we do not see any implications of this incentive for our findings. Data collection took place between June and September, 2011. Like many large North American cities, Toronto is a context in which discourses of ethical consumption have received prominent media attention for many years, so we assumed that there was sufficient opportunity for broad consumer engagement with ethical food consumption.

\section{Variable construction}

Our first dependent variable was a dichotomous measure of intention to purchase organic food. We constructed this measure through answers to the question "The last time I went shopping, I made an effort to buy organic food.” People who agreed with this statement were categorized as having an intention to buy organic food, while people who disagreed or were neutral to this statement were categorized as not having an intention. Our second dependent variable employed the local food analog question to the first dependent variable ("The last time I went shopping, I made an effort to buy local food”).

Although there is debate about what constitutes local food, we allowed respondents to employ their own definitions of local food because we were interested in examining their

\footnotetext{
${ }^{3}$ We control in our models (without reporting results) for whether the survey was administered at a farmers' market, and our multivariate results are not driven by the sampling method. All survey locations offer local and organic food options. For a comprehensive discussion of the advantages and disadvantages and data implications of intercept surveys, see Blair, Czaja, and Blair (2014), especially chapters 4 and 5. A copy of the survey is available on request from the fourth author.

${ }^{4}$ Respondents were required to read and write English in order to complete the survey. Participants signed a consent form which gave the researchers permission to use their information anonymously, and they were supplied with their own copy of the consent form.
} 
Table 1: Descriptive Statistics

\begin{tabular}{|c|c|c|}
\hline & Frequency & Percentage \\
\hline \multicolumn{3}{|l|}{ Gender } \\
\hline Male & 461 & 39.1 \\
\hline Female & 719 & 60.9 \\
\hline \multicolumn{3}{|l|}{ Age } \\
\hline $18-30$ & 462 & 39.3 \\
\hline $31-40$ & 276 & 23.5 \\
\hline $41-50$ & 207 & 17.6 \\
\hline $51-60$ & 141 & 12.0 \\
\hline$>60$ & 89 & 7.6 \\
\hline \multicolumn{3}{|l|}{ Minority Status } \\
\hline White & 757 & 65.5 \\
\hline Visible minority & 398 & 34.5 \\
\hline \multicolumn{3}{|l|}{ Income (x 1000) } \\
\hline$<20$ & 207 & 19.0 \\
\hline $20-30$ & 122 & 11.2 \\
\hline $30-40$ & 119 & 10.9 \\
\hline $40-60$ & 173 & 15.8 \\
\hline $60-100$ & 233 & 21.3 \\
\hline$>100$ & 238 & 21.8 \\
\hline \multicolumn{3}{|l|}{ Education } \\
\hline High school or less & 227 & 19.4 \\
\hline College or trade diploma & 128 & 11.0 \\
\hline Some university & 229 & 19.6 \\
\hline Undergraduate degree & 337 & 28.9 \\
\hline Professional or graduate degree & 247 & 21.2 \\
\hline \multicolumn{3}{|l|}{ Children in Household (dummy variables) } \\
\hline None Under 5 & 971 & 83.6 \\
\hline At least one under 5 & 190 & 16.4 \\
\hline None 6-12 & 1025 & 88.2 \\
\hline At least one 6 - 12 & 137 & 11.8 \\
\hline None 13-18 & 1103 & 86.3 \\
\hline At least one $13-18$ & 159 & 13.7 \\
\hline \multicolumn{3}{|l|}{ Organic Consumption (Intention) } \\
\hline High Organic & 681 & 60.7 \\
\hline Low Organic & 441 & 39.3 \\
\hline \multicolumn{3}{|l|}{ Local Consumption (Intention) } \\
\hline High Local & 489 & 42.9 \\
\hline Low Local & 651 & 57.1 \\
\hline \multicolumn{3}{|l|}{ Primary Motivations } \\
\hline Collectivist & 366 & 35.6 \\
\hline Individualist & 661 & 64.4 \\
\hline
\end{tabular}

Note: Based on 1200 surveys administered; not all questions were answered by all respondents. 
understandings of their consumption. ${ }^{5}$ We acknowledge that there are gaps between attitudes, intentions, and behaviors (Zepeda \& Nie, 2012). Nonetheless, the study of consumer intentions is a large and important area of research, including within the study of ethical consumption. McEachern et al. (2010) argue that focusing on intention is important due to the acknowledged barriers to purchasing (time, convenience, and cost). Additionally, as Elliott (2013) writes, the study of consumer intentions is important for investigating connections between consumer motivations and product choices, and can do so in ways that are sometimes obscured in studies of purchasing behaviors.

Our key independent variables were derived from reported motivations for intentions to purchase ethical foods, based on survey questions that asked respondents their motivations for buying organic or local food and to identify which motivation was their primary one. The questions provided a list of potential motivations, including health protection, environmental concerns, farmer livelihoods, social justice in developing countries, concern for workers' health and safety, and the option for writing in another motivation. Based on respondents' choice of primary motivation, we created two dummy variables that represent respondents' motivation as either "individualist” or “collectivist." Individualist motivations included health protection and the taste, freshness, convenience, or quality of food. Collectivist motivations included environmental concerns, social justice, farmer livelihood, and concern for workers' health and safety. In order to address questions specific to health motivations, we also created two further dummy variables. One variable represents the primary motivation of health concerns, and the other represents the remaining individualist concerns (food taste, freshness, etc.).

Our other independent variables were those sociodemographic variables most commonly employed in consumption studies, namely gender (female $=1$ ), race (minority $=1)^{6}$, age, income, education, and the presence of children in the household. ${ }^{7}$ In addition, as the survey was administered at both conventional food stores and farmer's markets, we controlled in our models for survey location (not reported in tables).

\section{Analysis}

We used multivariate regression to estimate the effects of the independent variables on each of our two dependent variables. As each of our dependent variables was dichotomous, we employed logistic regression. Our models were structured according to a logic that allowed us to first understand the sociodemographic characteristics that are associated with the intention to buy

\footnotetext{
${ }^{5}$ It is also true that in the Toronto area, grocery stores, both expensive chains and bargain chains, make efforts to identify items as local whenever possible, most commonly with signs that indicate when food is from the province of Ontario.

${ }^{6}$ Due to small cell sizes, we are forced to collapse racial groups other than White into a single category.

${ }^{7}$ For this variable, we used responses to survey questions that asked about the presence of children 5 years of age or younger living at home, 6 -12 years of age living at home, or $13-18$ years of age living at home. We coded respondents as either having at least one child in a given bracket or having none in a category. It was possible for respondents to be coded as having children in more than one bracket.
} 
organic food and local food respectively, as well as the effect of the presence of children in the household. Following that initial model, we introduced the focal independent variable of consumer motivation. Specifically, we assessed the relationship of collectivist motivations relative to individualist motivations with the intention to purchase organic food and to purchase local food. In order to further interrogate how motivations influence intention to purchase, in the third model we examined collectivist motivations and health motivations separately from other individualist motivations. We turn next to our findings, first for organic, and then for local food.

\section{Findings}

\section{Organic food as family health strategy}

Table 2 presents our results regarding intention to purchase organic food. In model 1, being female and in an age group older than the reference group of 18-30 were significantly and positively correlated with intention to purchase organic food. As with prior research, income had no relationship to the dependent variable. Surprisingly, there was no correlation in our sample between education and intention to purchase organic food either. In contrast, the effect of having children under the age of 5 was especially strong, with the odds ratio indicating that those with children 5 and under in the house were more than twice as likely as other consumers to intend to purchase organic food. Having older children in the house was not significantly associated with the intention to purchase organic food.

In model two we introduced the variable of holding collectivist motivations, omitting individualist motivations as the reference category. We saw a slight improvement in the model fit and virtually no changes in the associations of the statistically significant sociodemographic variables. Regarding the motivations themselves, there was no significant difference in the likelihood of holding a collectivist vs. an individualist primary motivation among those who intend to purchase organic food. In other words, both motivations existed among these shoppers. The third model introduced a dummy variable for holding collective motivations and another dummy variable for holding health motivations, with the omitted reference category being holding individualist motivations other than health.

We learned two important things from these odds ratios. First, health motivations were significantly and strongly correlated with intention to purchase organic food. Second, collectivist motivations were significantly correlated with intention to purchase organic food at the $p<0.1$ level of significance, now that the comparison group is individualist motivations apart from health. This change in the odds ratio for collectivist motivations between model two and model three suggests that there was both an important difference with holding individualist motivations apart from health (i.e., taste and freshness and food quality), and a degree of commonality between the tendency to hold collectivist motivations and health motivations. ${ }^{8}$ Importantly, we saw the odds

\footnotetext{
${ }^{8}$ In results not shown here, we also ran a model with collectivist motivations as the omitted reference group. In that model, the odds ratio for health motivations was not statistically significant.
} 
Table 2: Logistic regression of sociodemographics and motivations on intention to purchase organic food

\begin{tabular}{|c|c|c|c|}
\hline & Model 1 & Model 2 & Model 3 \\
\hline Female (reference = Male) & $1.41^{*}$ & $1.40^{*}$ & $1.38^{*}$ \\
\hline & .151 & .151 & .151 \\
\hline \multicolumn{4}{|l|}{ Age (reference = 18-30) } \\
\hline \multirow[t]{2}{*}{$31-40$} & $2.02 * * *$ & $1.99 * *$ & $1.98^{* * *}$ \\
\hline & .201 & .201 & .201 \\
\hline \multirow{2}{*}{$41-50$} & $1.59 *$ & $1.58 *$ & $1.52 *$ \\
\hline & .214 & .214 & .214 \\
\hline \multirow{2}{*}{$51-60$} & $1.94 * *$ & $1.95 * *$ & $1.95^{* *}$ \\
\hline & .238 & .238 & .238 \\
\hline \multirow[t]{2}{*}{$>60$} & $1.85^{*}$ & $1.81^{*}$ & $1.78^{*}$ \\
\hline & .302 & .303 & .302 \\
\hline \multicolumn{4}{|l|}{ Race (reference = Non-White) } \\
\hline \multirow[t]{2}{*}{ White } & 1.33 & 1.36 & 1.36 \\
\hline & .161 & .163 & .161 \\
\hline \multicolumn{4}{|l|}{ Income (in thousands) (reference $=<20$ ) } \\
\hline \multirow[t]{2}{*}{$20-40$} & 1.05 & 1.05 & 1.05 \\
\hline & .258 & .238 & .258 \\
\hline \multirow[t]{2}{*}{$40-60$} & 0.84 & 0.85 & 0.83 \\
\hline & .241 & .258 & .241 \\
\hline \multirow[t]{2}{*}{$60-100$} & 1.16 & 1.16 & 1.15 \\
\hline & .253 & .241 & .253 \\
\hline \multirow[t]{2}{*}{$>100$} & 0.96 & 0.96 & 0.99 \\
\hline & .238 & .253 & .238 \\
\hline \multicolumn{4}{|l|}{ Education (reference = High school or less) } \\
\hline \multirow[t]{2}{*}{ College or trade diploma } & 1.12 & 1.11 & 1.08 \\
\hline & .281 & .281 & .281 \\
\hline \multirow[t]{2}{*}{ Some university } & 1.32 & 1.31 & 1.28 \\
\hline & .242 & .242 & .242 \\
\hline \multirow[t]{2}{*}{ Undergraduate degree } & 1.47 & 1.46 & 1.43 \\
\hline & .231 & .232 & .231 \\
\hline \multirow[t]{2}{*}{ Prof. or grad. degree } & 1.27 & 1.27 & 1.28 \\
\hline & .248 & .248 & .248 \\
\hline \multicolumn{4}{|l|}{ Children in Household (reference = no children) } \\
\hline \multirow[t]{2}{*}{5 or under } & $2.11^{* * *}$ & $2.11 * * *$ & $2.08^{* * *}$ \\
\hline & .213 & .213 & .213 \\
\hline \multirow[t]{2}{*}{$6-12$} & 1.00 & .978 & .972 \\
\hline & .235 & .239 & .235 \\
\hline \multirow[t]{2}{*}{$13-18$} & 0.64 & 0.85 & 0.66 \\
\hline & .239 & .239 & .239 \\
\hline \multicolumn{4}{|l|}{ Primary motivation (reference = individualist) } \\
\hline Collectivist & & .85 & \\
\hline & & .154 & \\
\hline Primary motivation (reference $=$ individualist apart $\mathrm{fr}$ & & & \\
\hline Collectivist & & & $2.27 \wedge$ \\
\hline & & & .461 \\
\hline Health & & & $2.83^{* *}$ \\
\hline$N$ & & & .454 \\
\hline iv & 917 & 917 & 917 \\
\hline Pseudo & 0.10 & 0.11 & 0.11 \\
\hline$\wedge \mathrm{p}<0.10 * \mathrm{p}<0.05 \quad * * \mathrm{p}<0.01 \quad * * * \mathrm{p}<0.001$ & & & \\
\hline
\end{tabular}

Note: Table reports odds ratios. All models control for location where survey was administered. Standard deviations are in parentheses. 
ratio for gender and presence of young children in the house remain significant, with rather large effect sizes.

\section{Local food as collectivist concern}

Table 3 presents the results of our logistic regression model of intention to purchase local food. In our first model estimating intention to purchase local food, we saw that women were more likely than men, consumers 30 years of age and younger were dramatically less likely relative to all older age groups, and that non-White consumers were less likely than White consumers. Income was not associated with intention to purchase local food, although having an undergraduate degree made a respondent much more likely to intend to purchase local food relative to those with a high school diploma or less education. In contrast to the case for organic food, there was no significant relationship with having children under five years old in the house and the intention to purchase local food.

In model 2 we introduced the dummy variable of having collectivist motivations, omitting the variable for individualist motivations as the reference category. While the sociodemographic variables remained mainly unchanged, the model fit improved, and we saw that there was a statistically significant relationship with holding collectivist motivations. This was a clear contrast to the case for organic food. In model 3 we included the dummy variable for collectivist motivations and the dummy variable for holding health motivations, while the omitted reference category was holding individualist motivations apart from health. Compared to when the reference category included health, we saw that collectivist motivations had an even clearer and stronger relationship with intention to purchase local food. At the same time, health motivations themselves were not significantly correlated with the dependent variable, relative to other individualist motivations. Interestingly, the odds ratio for having an undergraduate degree remained significant and large across the models, and the odds ratio for having a professional or graduate degree reached significance at the $\mathrm{p}<0.05$ level in the final model. We saw here an interesting set of relationships including race, education, and collectivist motivations.

\section{Multiple motivations}

The regression results suggested that multiple motivations exist for both organic and local food consumption. To illustrate and directly compare the different primary motivations behind intention to purchase local and organic food, Figure 1 displays the probability of having individualist vs. collectivist motivations for intention to purchase organic vs. local food while holding all other variables at their average logit values. 
Table 3: Logistic regression of sociodemographics and motivations on intention to purchase local food

\begin{tabular}{|c|c|c|c|}
\hline & Model 1 & Model 2 & $\underline{\text { Model } 3}$ \\
\hline \multirow[t]{2}{*}{ Female (reference $=$ Male) } & $\overline{1.50 * *}$ & $\overline{1.58 * *}$ & $1.55^{* *}$ \\
\hline & .154 & .157 & .157 \\
\hline \multicolumn{4}{|l|}{ Age (reference = 18-30) } \\
\hline \multirow[t]{2}{*}{$31-40$} & $3.08^{* * *}$ & $3.40^{* * *}$ & $3.40^{* * *}$ \\
\hline & .213 & .217 & .218 \\
\hline \multirow[t]{2}{*}{$41-50$} & $2.75^{* * *}$ & $2.93 * * *$ & $2.83 * * *$ \\
\hline & .217 & .220 & .221 \\
\hline \multirow[t]{2}{*}{$51-60$} & $3.17^{* * *}$ & $3.17^{* * *}$ & $3.16^{* * *}$ \\
\hline & .250 & .252 & .253 \\
\hline \multirow[t]{2}{*}{$>60$} & $3.11^{* * *}$ & $3.48^{* * *}$ & $3.44 * * *$ \\
\hline & .323 & .327 & .328 \\
\hline \multirow[t]{2}{*}{ White (reference = non-white) } & $1.85^{* * *}$ & $1.71^{* *}$ & $1.71^{* *}$ \\
\hline & .161 & .164 & .164 \\
\hline \multicolumn{4}{|c|}{ Income (in thousands) (reference $=<20$ ) } \\
\hline \multirow[t]{2}{*}{$20-40$} & 0.88 & 0.86 & 0.86 \\
\hline & .238 & .242 & .243 \\
\hline \multirow[t]{2}{*}{$40-60$} & 1.13 & 1.16 & 1.10 \\
\hline & .257 & .261 & .248 \\
\hline \multirow[t]{2}{*}{$60-100$} & 1.08 & 1.08 & 1.06 \\
\hline & .246 & .247 & .248 \\
\hline \multirow[t]{2}{*}{$>100$} & 0.99 & 0.99 & 1.01 \\
\hline & .260 & .263 & .264 \\
\hline \multicolumn{4}{|c|}{ Education (reference = High school or less) } \\
\hline \multirow{2}{*}{ College or trade diploma } & 1.16 & 1.21 & 1.19 \\
\hline & .280 & .282 & .282 \\
\hline \multirow[t]{2}{*}{ Some university } & 1.28 & 1.34 & 1.32 \\
\hline & .241 & .244 & .244 \\
\hline \multirow[t]{2}{*}{ Undergraduate degree } & $2.18^{* *}$ & $2.23 * *$ & $2.24 * *$ \\
\hline & .236 & .238 & .239 \\
\hline \multirow[t]{2}{*}{ Prof. or grad. degree } & 1.62 & 1.63 & $1.65^{*}$ \\
\hline & .231 & .255 & .256 \\
\hline \multicolumn{4}{|l|}{ Children in Household } \\
\hline \multirow[t]{2}{*}{5 or under } & 1.45 & 1.50 & 1.47 \\
\hline & .241 & .233 & .233 \\
\hline \multirow[t]{2}{*}{$6-12$} & 0.76 & 0.82 & 0.81 \\
\hline & .241 & .243 & .236 \\
\hline \multirow[t]{2}{*}{$13-18$} & 0.63 & 0.62 & 0.64 \\
\hline & .231 & .235 & .236 \\
\hline \multicolumn{4}{|c|}{ Primary motivation (reference $=$ individualist) } \\
\hline \multirow[t]{2}{*}{ Collectivist } & & $2.072 * * *$ & \\
\hline & & .163 & \\
\hline Primary motivation (reference $=$ & & & \\
\hline Collectivist & & & $3.95 * * *$ \\
\hline & & & .414 \\
\hline Health & & & 1.99 \\
\hline & & & .406 \\
\hline $\mathrm{N}$ & 941 & 941 & 941 \\
\hline Pseudo & 0.17 & 0.21 & 0.21 \\
\hline
\end{tabular}




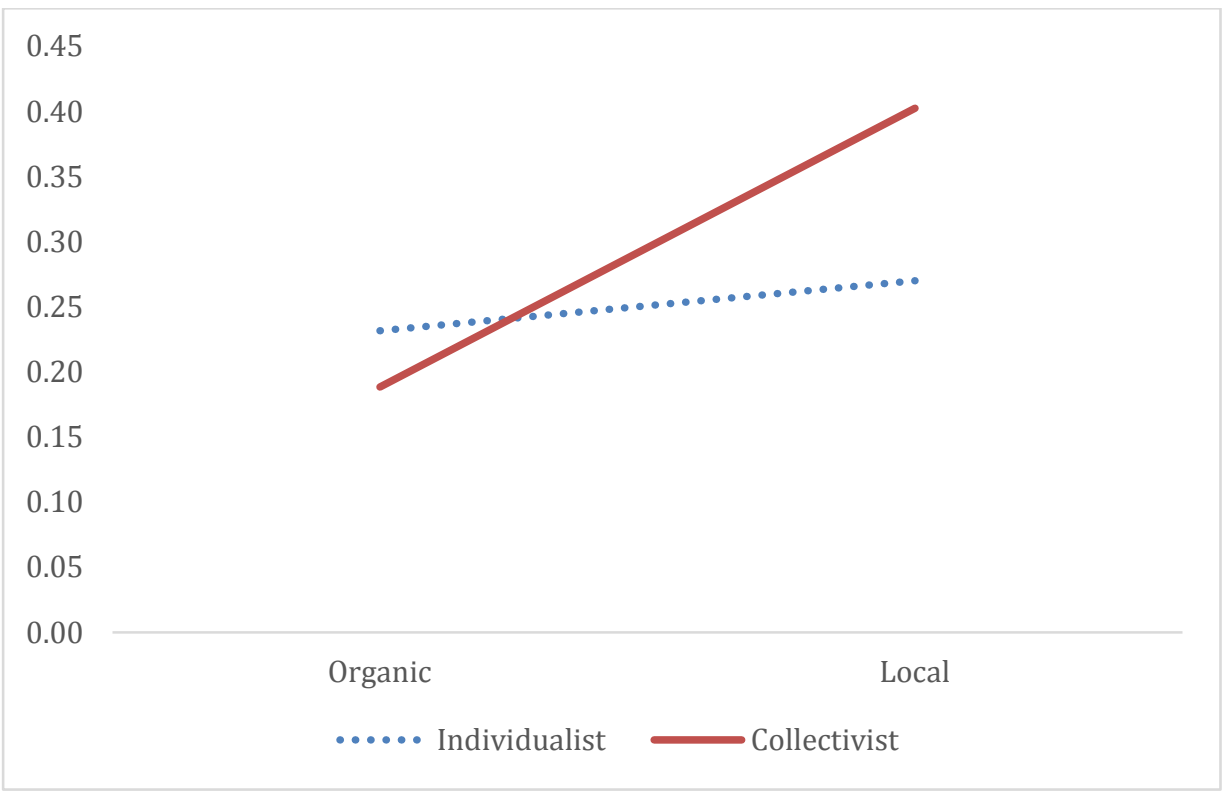

Figure 1: Fitted probabilities of having primary individualist and collectivist motivations for intention to purchase organic and local food

Individualist motivations were related to both organic and local food intention to purchase, with a just slightly higher correlation with local intention. Collectivist motivations were less strongly related to organic intention and much more strongly related to local consumption. We can see that both organic and local food consumption had multiple motivations. However, we can clearly see that organic and local consumption intentions related quite differently to collectivist motivations.

\section{Discussion and conclusion}

We analyzed survey data on consumer demographics and motivations for intention to purchase organic and local food in order to understand the multidimensionality of "ethical” food options. Our key findings include a difference in primary motivation for consumers intending to purchase organic vs. local food. Intention to purchase local food was more strongly motivated by collectivist concerns than is organic food. In addition, intention to purchase local food is associated with well-educated, White, women consumers. In contrast, we found that intention to purchase organic food, but not local food, was strongly associated with women who have very young children in the house. This relationship to children under five conforms to one of the (controversial) strands of organic food consumption discourse that is prominent in the market, which emphasizes the healthfulness of organic food, especially for young children, who have been found in some scientific studies to be most strongly affected by pesticides and ablest to 
benefit from the maximum nutritional qualities that organic food is often claimed to possess (Lu et al., 2006). Our findings strongly suggest that organic and local food should be conceptualized as distinct forms of ethical consumption.

Research on ethical consumption tends to share the popular understanding that motivations for ethical consumption are either individualist or collectivist (accepting, of course, that consumers can be motivated by both kinds of concerns). Within this framework, concerns for healthfulness are understood as individualist. However, to the extent that organic food consumption is often motivated by a desire among mothers for health protection of young children, we would argue that the individualist conceptualization of this motivation is not an accurate label.

Instead, we would point to earlier research on conventional (non-ethical) consumption that has identified motivations that can be usefully applied to the case of organic food consumption: specifically, Thompson's (1996) concept of caring consumption, Miller's (1998) concept of “shopping as sacrifice” (Miller, 1998), and MacKendrick’s (2010) concept of “precautionary consumption” (MacKendrick, 2010). What these three perspectives on consumption share is a framing of consumption as underscored by a sense of social connection and caring for others for whom consumers, particularly women, are personally responsible. In different ways, each applies well to our findings about the intention to purchase organic food.

At the same time, the application of these perspectives on consumption to organic food complicates the usual individualist vs. collectivist distinction used to understand ethical consumption. This complication introduces a distinction between collectivist motivations that are concerned with distant others (society, workers, the world) and collectivist concerns for proximate others (those to whom we have personal obligations). Our findings provide broader support for the findings of Cairns, Johnston, and MacKendrick (2013), which show that mothers' organic food shopping is influenced by contemporary mothering norms. These norms frame feeding children as an opportunity to protect their health and purity, an important goal best pursued by avoiding pollutants while maximizing nutrition. The authors argue that this generates a mothering ideal that they refer to as feeding the "organic child.” Health protection motivations for the self are clearly individualist, but health protection motivations for small children are selforiented in a meaningfully different way. For this reason, we propose that research on organic food consumption must be open to more nuanced accounts of how ethical consumption is motivated in more complicated ways than can be accommodated by an individualist vs. collectivist dichotomy. The "win-win” formulation of ethical consumption common in popular and marketing discourses does not quite capture the range of goals and needs that consumers must consider in their ethical food consumption choices, some of which are intermediate between "self" and "society."

For local food, we found that the presence of young children in the household is not an important influence on orientation toward local food consumption. Despite the room for income to play a role, since local foods are more expensive in the context of the survey location of Toronto, income was not a significant predictor in any of the models. In contrast, education was 
positively related to an orientation toward local foods, as was White racial self-identification. The race finding was particularly interesting in the context of multicultural Toronto, where there is not a strong pattern of White/non-White residential segregation. In other words, the racial difference was not attributable to differential access to local food, especially since the locations surveyed are urban and easily accessed by car or by public transportation. We speculate that the association between education, race, and the collectivist motivations for intention to purchase local foods reflects a socially-bounded culture of civic-minded food consumption (Alkon \& McMullen, 2011). Among some highly educated, White, female consumers, buying local foods may be a cultural practice that is given meaning by its collectivist ethical implications, such as community building, support of the local economy, and environmental protection (Alkon \& McMullen, 2011).

We have focused in this paper on clarifying the motivations behind different forms of food consumption typically considered “ethical." From a food scholarship perspective, while the pros and cons of the growth of the organic and local food sectors have been discussed (e.g., Goodman, Dupuis, \& Goodman, 2012; Obach, 2016), there has been relatively little discussion of the respective motivations that underlie organic and local food purchasing. The alternative food market has mainly been approached with a win-win framing that promotes ethical consumption as a way to satisfy seemingly disparate motivations (Johnston \& Cairns, 2012). While critiques of this win-win framing and its intersections with neoliberal ideologies are important, it is also important to empirically study what motivates consumers, and to disaggregate the motivations for various products within alternative food networks. While civicminded motivations may inspire consumers' intentions to buy local foods, the drive to purchase organic food is quite distinct. Organic food purchases may ultimately support political ends such as environmental protection, as well as other collectivist motivations. Nonetheless, we found in our survey an important primary consumer motivation for intention to purchase organic food: the responsibilities of care work, particularly the health concerns of mothers of small children looking to protect and nurture young bodies.

\section{References}

Adams, D. C., \& M. J. Salois. (2010). Local versus organic: A turn in consumer preferences and willingness-to-pay. Renewable Agriculture and Food Systems, 25(4), 331-341.

Aguirre, J. A. (2007). The farmer's market organic consumer of Costa Rica. British Food Journal, 109(2), 145-154.

Ahmad, S. N. B., \& Juhdi, N. (2010). Organic food: A study on demographic characteristics and factors influencing purchase intentions among consumers in Klang Valley, Malaysia. International Journal of Business and Management, 5(2), 105-118. 
Akgüngör, S., Miran B., \& Abay, C. (2010). Consumer willingness to pay for organic food in urban Turkey. Journal of International Food \& Agribusiness Marketing, 22(3-4), 299-313.

Alkon, A. H., \& McCullen, C. G. (2011). Whiteness and farmers markets: Performances, perpetuations... contestations?. Antipode, 43(4), 937-959.

Bianchi, C., \& Mortimer, G. (2015). Drivers of local food consumption: A comparative study. British Food Journal, 117(9), 2282-2299.

Bingen, J., Sage, J., \& Sirieix, L. (2011). Consumer coping strategies: A study of consumers committed to eating local. International Journal of Consumer Studies, 35(4), 410-419.

Blair, J., Czaja, R. F., \& Blair, E. (2014). Designing surveys: A guide to decisions and procedures, $3^{\text {rd }}$ edition. Thousand Oaks, CA: Sage Publications, Inc.

Brown, C. (2003). Consumers preferences for locally produced food: A study in southeast Missouri. American Journal of Alternative Agriculture, 18(4), 213-224.

Bureau of Labor Statistics. (2013). American Time Use Survey. Retrieved from http://www.bls.gov/tus/charts/household.htm

Cairns, K., Johnston, J., \& MacKendrick, N. (2013). Feeding the 'organic child': Mothering through ethical consumption. Journal of Consumer Culture, 13(2), 97-118.

Carpio, C. E., \& Isengildina-Massa, O. (2009). Consumer willingness to pay for locally grown products: The case of South Carolina. Agribusiness, 25(2), 412-426.

Crane, A., \& Matten, D. (2003). Business ethics: A European perspective, managing corporate citizenship and sustainability in the age of globalization. Oxford: Oxford University Press.

Cranfield, J., Henson, S., \& Blandon, J. (2012). The effect of attitudinal and sociodemographic factors on the likelihood of buying locally produced food. Agribusiness, 28(2), 205-221.

Curl, C. L., Beresford, S. A. A., Hajat, A., Kaufman, J. D., Moore, K., Nettleton, J. A., \& DiezRodux, A. V. (2013). Associations of organic produce consumption with socioeconomic status and the local food environment: Multi-ethnic study of atherosclerosis (MESA). PloS one, 8(7), e69778.

Dettmann, R. L., \& Dimitri, C. (2009). Who’s buying organic vegetables? Demographic characteristics of US consumers. Journal of Food Products Marketing, 16(1), 79-91.

Dimitri, C., \& Dettman, R. L. (2012). Organic food consumers: what do we really know about them? British Food Journal, 114(8), 1157-1183.

Elliott, R. (2013). The taste for green: The possibilities and dynamics of status differentiation through 'green' consumption. Poetics, 41, 294-322. 
González, J. A. A. (2009). Market trends and consumer profile at the organic farmers market in Costa Rica. British Food Journal, 111(5), 498-510.

Goodman, D., Dupuis, E. M., \&Goodman, M. K. (2012). Alternative food networks: Knowledge, practice, and politics. New York: Routledge.

Haghiri, M., Hobbs, J. E., \& McNamara, M. L. (2009). Assessing consumer preferences for organically grown fresh fruit and vegetables in eastern New Brunswick. International Food and Agribusiness Management Review, 12(4), 81-100.

Hamazoui Essoussi, L., \& Zahaf, M. (2008). Profiling organic food consumers: Motivations, trust orientations and purchasing behaviour. Journal of International Business and Economics, 8(2), 25-39.

Hemmerling, S., Hamm, U., \& Spiller, A. 2015. Consumption behavior regarding organic food from a marketing perspective-A literature review. Organic Agriculture, 5(4), 277-313.

Hughner, R. S., McDonah, P., Prothero, A., Shultz II, C. J., \& Stanton. J. (2007). Who are organic food consumers? A compilation and review of why people purchase organic food. Journal of Consumer Behaviour, 6, 94-110.

Jensen, J. D., \& Mørkbak, M. R. (2013). Role of gastronomic, externality and feasibility attributes in consumer demand for organic and local foods: The case of honey and apples. International Journal of Consumer Studies, 37, 634-641.

Johnston, J. (2008). The citizen-consumer hybrid: ideological tensions and the case of Whole Foods Market. Theory and Society, 37(3), 229-270.

Johnston, J., \& Cairns, K. (2012). Eating for Change. In S. Banet-Wiser \& R. Mukherji (Eds.), Commodity activism: Cultural resistance in neoliberal times (pp. 219-239). New York: NYU Press.

Khan, F., \& Prior, C. (2010). Evaluating the urban consumer with regard to sourcing local food: A heart of England study. International Journal of Consumer Studies, 34(2), 161-168.

Krystallis, A., Vassallo, M., Chryssohoidis, G., \& Perrea, T. (2008). Societal and individualistc drivers as predictors of organic purchasing revealed through a portrait value questionnaire (PVQ)-based inventory. Journal of Consumer Behaviour, 7, 164-187.

Kriwy, P., \& Mecking, R. (2012). Health and environmental consciousness, costs of behaviour and the purchase of organic food. International Journal of Consumer Studies, 36(1), 30-37.

Lee, H. (2016). Individual and situational determinants of U.S. consumers’ buying behavior of organic foods. Journal of International Food \& Agribusiness Marketing, 28(2), 117-131. 
Lockie, S., Lyons, K., Lawrence, G., \& Mummery, K. (2002). Eating ‘green’: motivations behind organic food consumption in Australia. Sociologia Ruralis, 42(1), 23-40.

Lodorfos, G. N., \& Dennis, J. (2008). Consumers' intent: In the organic food market. Journal of Food Products Marketing, 14(2), 17-38.

Lundblad, L., \& Davies, I. A. (2016). The values and motivations behind sustainable fashion consumption. Journal of Consumer Behaviour, 15(2), 149-162.

Magnusson, M. K., Arvola, A., \& Hursti, U. (2001). Attitudes towards organic foods among Swedish consumers. British Food Journal, 103(3), 209-226.

McEachern, M. G., \& McClean, P. (2002). Organic purchasing motivations and attitudes: are they ethical? International Journal of Consumer Studies, 26(2), 85-92.

McEachern, M. G., Warnaby, G., Carrigan, M., \& Szmigin, I. (2010). Thinking locally, acting locally? Conscious consumers and farmers' markets. Journal of Marketing Management, 26(5/6), 395-412.

MacKendrick, N. A. (2010). Media framing of body burdens: Precautionary consumption and the individualization of risk. Sociological Inquiry, 80(1), 126-149.

Megicks, P., Memery, J., \& Angell, R. J. (2012). Understanding local food shopping: Unpacking the ethical dimension. Journal of Marketing Management, 28(3-4), 264-289.

Miller, D. (1998). Theory of Shopping. Ithaca: Cornell University Press.

Obach, B. K. (2016). Organic struggle: The movement for sustainable agriculture in the United States. Cambridge, MA: The MIT Press.

Quah, S., \& Tan, A. K. G. (2009). Consumer purchase decisions of organic food products: An ethnic analysis. Journal of International Consumer Marketing, 22(1), 47-58.

Reifer, A., \& Hamm, U. (2011). Organic food consumption in families with juvenile children. British Food Journal, 113(6), 797-808.

Roitner-Schobesberger, B., Darnhofer, I., Somsook, S., \& Vogl, C. R. (2008). Consumer perceptions of organic foods in Bangkok, Thailand. Food Policy, 33(2), 112-121.

Sangkumchaliang, P., \& Huang, W. (2012). Consumers’ perceptions and attitudes of organic food products in northern Thailand. International Food and Agribusiness Management Review, 15(1), 87-102.

Schrank, Z., \& Running, K. (2016). Individualist and collectivist consumer motivations in local organic food markets. Journal of Consumer Culture, online first

DOI:10.1177/1469540516659127 
Schuitema, G., \& De Groot, J. (2015). Green consumerism: The influence of product attributes and values on purchasing intentions. Journal of Consumer Behaviour, 14, 57-69.

Sønderskov, K., M, \& Daugbjerg, C. (2011). The state and consumer confidence in eco-labeling: organic labeling in Denmark, Sweden, The United Kingdom and The United States. Agriculture and Human Values, 28(4), 507-514.

Thøgersen, J., \& Zhou, Y. (2012). Chinese consumers' adoption of a 'green' innovation-The case of organic food. Journal of Marketing Management, 28(3-4), 313-333.

Thompson, C. (1996). Caring consumers: Gendered consumption meanings and the juggling lifestyle. Journal of Consumer Research, 22, 388-407.

Tregear, A., \& Ness, M. (2005). Discriminant analysis of consumer interest in buying locally produced foods. Journal of Marketing Management, 21(1-2), 19-35.

Weatherell, C., Tregear, A., \& Allinson, J. (2003). In search of the concerned consumer: UK public perceptions of food, farming and buying local. Journal of Rural Studies, 19(2), 233244.

Willis, M., \& Schor, J. (2012). Does changing a light bulb lead to changing the world?: Political action and the conscious consumer. The ANNALS of the American Academy of Political and Social Science, 644(1), 160-190.

Zepeda, L., \& Deal, D. (2009). Organic and local food consumer behaviour: Alphabet theory. International Journal of Consumer Studies, 33(6), 697-705.

Zepeda, L., \& Li, J. (2007). Characteristics of organic food shoppers. Journal of Agricultural and Applied Economics, 39(1), 17.

Zepeda, L., \& Li, J. (2006). Who buys local food? Journal of Food Distribution Research, 37(3), $1-11$.

Zepeda, L. \& Nie, C. (2012). What are the odds of being an organic or local food shopper? Multivariate analysis of US food shopper lifestyle segments. Agriculture and Human Values, 29, 467-480. 